\title{
A conscientização linguística e a didática do multilinguismo em contextos de contato português- Hunsrückisch
}

\author{
Karen Pupp Spinasséa \\ Maria Lidiani Käfer ${ }^{b}$
}

\begin{abstract}
Resumo
O Hunsrückisché uma das línguas de imigração de maior abrangência no Brasil, já tendo sido co-oficializada em dois municípios brasileiros (Antônio Carlos, em Santa Catarina, e Santa Maria do Herval, no Rio Grande do Sul). De forma geral, portanto, algumas ações no âmbito das políticas linguísticas e dos direitos linguísticos vêm sendo tomadas, a fim de que a diversidade linguística e cultural das regiões de contato com o Hunsrückisch seja respeitada. Dentre essas ações estão alguns projetos de pesquisa que se ocupam de investigar tanto as práticas de linguagem quanto as atitudes linguísticas presentes nas regiões, buscando colaborar na manutenção da língua e da identidade deixadas de herança pelos antepassados. Nesse sentido, o presente artigo traz alguns resultados de uma pesquisa-ação realizada em duas escolas de diferentes comunidades de fala de Hunsrückisch, que teve como objetivo utilizar a conscien tização linguística para despertar a sensibilidade e o respeito a diferentes variedades. O objetivo da pesquisa foi apontar caminhos que contribuam para o desenvolvimento de atitudes positivas do aprendiz diante da diversidade linguística em que se encontra (incluindo, neste caso, as linguas minoritárias), pensando os fundamentos para uma Didática do Multilinguismo que se permita partir das línguas e culturas locais para alcançar o aprendizado de outras linguas que venham a despertar o interesse.
\end{abstract}

Palavras-chave: Conscientização Linguística. Hunsrückisch. Politicas Linguísticas. Didática do Multilinguismo. Atitudes Linguísticas. 


\section{Introdução}

O presente artigo traz resultados de uma pesquisa-ação que abordou o ensino de alemão-padrão como língua adicional em contextos de contato linguístico português-Hunsrückisch (Pt-Hr). Como já se trata de contextos multilíngues, nos quais indivíduos dominam uma língua de origem alemã que desempenha o papel de koiné para a comunicação entre diversas comunidades, a presença do alemão-padrão na escola sempre desperta questões centrais: em que medida o "alemão" falado nas casas desses indivíduos (no caso, o Hunsrückisch) difere do alemão aprendido na escola? Seria este a versão correta daquele? Seria o "alemão falado em casa" uma forma "incorreta", que prejudica o aprendizado do alemão-padrão, ou seria ele uma ponte para se aprender a variedade standard ensinada na escola?

Esses questionamentos, bastante difundidos em comunidades de fala de Hunsrückisch, fazem falantes e nãofalantes desenvolverem imagens distorcidas, na sua maioria negativas, em relação à língua minoritária. Essas atitudes negativas, já tematizadas em estudos anteriores (ALTENHOFEN, 2004; PUPP SPINASSÉ, 2005; SCHNEIDER, 2007), prejudicam o plurilinguismo, pois levam alguns falantes a não mais quererem falar a língua minoritária (KÄFER, 2013, 52), estigmatizando-a como "menor" (de menor valor). Esses mesmos estudos também já alertaram para a necessidade de uma política linguística própria para tratar de questões pertinentes à Educação Linguística em comunidades de contato Pt-Hr.

De acordo com Bagno e Rangel (2005), a educação linguística inicia-se desde o nascimento do indivíduo, do convívio com a família, com o meio social e cultural, e deve ser definida como

o conjunto de fatores socioculturais que, durante toda a existência de um indivíduo, lhe possibilitam adquirir, desenvolver e ampliar o conhecimento de/sobre sua língua materna, de/sobre outras línguas, sobre a linguagem de um modo mais geral e sobre todos os demais sistemas semióticos. Desses saberes, evidentemente, também fazem parte as crenças, superstições, representações, mitos e preconceitos que circulam na sociedade em torno da língua/ linguagem e que compõem o que se poderia chamar de imaginário linguístico ou, sob outra ótica, de ideologia linguística (BAGNO; RANGEL, 2005, p. 63). 
Com o propósito, portanto, de contribuir para um ensino de línguas baseado no preceito acima, procuramos discutir a presença da língua minoritária Hunsrückisch no âmbito escolar e, particularmente, no ensino de alemão-padrão como língua adicional (LA) em contexto de fala da variedade minoritária. As ações propostas nas escolas durante a pesquisa tinham o intuito de promover a reflexão acerca dos fundamentos de uma abordagem plural que tenha por fim a conscientização linguística, e, mais especificamente, buscar e testar formas de incluí-la como prática pedagógica em contextos bilíngues Pt$\mathrm{Hr}$, apontando alguns caminhos para que se possa trabalhar de forma efetiva com as especificidades linguísticas da região.

Se partirmos da ideia de que a língua é um bem simbólico, de que a linguagem é socialmente construída, na qual todos somos atores ativos dessa construção (Cf. BOURDIEU, 1998) e de que é também pelo instrumento da linguagem que o sujeito se torna hábil a fazer parte do processo democrático de seu país (SKUTNABB-KANGAS, 1988, p.14), está clara a necessidade de repensarmos o ensino de línguas nas escolas. A aula de língua estrangeira/adicional não deve ter como objetivo somente preparar o aluno para as competências da línguaalvo, tais como ler, escrever, falar ou compreender, mas sim prepará-lo para a formação de uma competência intercultural e plurilíngue (cf. BASTOS et al., 2008, p. 57).

Para atender às necessidades e especificidades locais, a inclusão de ferramentas pedagógicas que trabalhem com a diversidade e com a conscientização linguística mostra-se como algo possível e realizável dentro do currículo de ensino de línguas. Acreditamos, com base em Candelier et al. (2004), que uma abordagem de ensino que promova o respeito às diferentes línguas e culturas e uma comunicação intercultural, utilizando propostas didáticas que partam da realidade linguística do aluno, seja algo realmente efetivo e aplicável à prática, como veremos neste artigo.

\section{A Conscientização Linguística}

O termo "conscientização linguística" (do inglês language awareness), doravante $\mathrm{CL}$, é entendido aqui, conforme a Association of Language Awareness, como "um conhecimento 
1 Disponível em: $<$ h t t p : / / w w w . languageawareness. org/web.ala/web/tout php > - Último acesso em 23 de dezembro de 2016.

${ }^{2}$ De forma ampla, o termo "metacognição", de acordo com Ribeiro (2003), refere-se à tomada de consciência dos processos e das competências necessárias para a realização de uma tarefa e o controle ou autorregulação que capacita o indivíduo a avaliar a execução da tarefa e fazer correções quando necessário. explícito sobre a língua, uma percepção consciente e uma sensibilidade na aprendizagem de línguas, no ensino de línguas e no uso de línguas." ${ }^{1}$. Em complemento, de acordo com Donmall (1985, p. 7), um dos principais objetivos da CL é elevar o nível de interesse do aluno no aprendizado de uma L2. Porém, acredita-se que ela pode, também, contribuir para o desenvolvimento da aprendizagem de outra língua, ou ainda para a quebra de barreiras existentes entre estudantes de diferentes culturas e etnias, como as relatadas em estudos sociolinguísticos em situações de convívio entre nativos e imigrantes.

James (1996, p. 140), por sua vez, define conscientização linguística como a posse de metacognição ${ }^{2}$, não somente sobre a língua materna, mas sobre línguas em geral. $O$ autor defende em seu texto que, em uma aula de língua (seja ela de L1 ou L2), o professor deve dar liberdade para o aluno conversar sobre sua língua materna (referindo-se às línguas minoritárias) ou sobre alguma língua adicional, tanto separadamente quanto, e especialmente, sobre a relação que possa existir entre elas.

Hawkins (1999) introduziu nas discussões o uso da CL no ensino/aprendizagem de línguas como uma possível prática pedagógica a ser adotada. Ele argumenta que o foco do professor deveria partir do ponto de vista do aluno. Desse modo, nas aulas de língua materna ou adicional, o aluno deveria ser estimulado a trazer seus questionamentos sobre o funcionamento das línguas em questão e o papel delas na sua vida. Da mesma forma, Jessner (2008) também não limita as atividades voltadas para a promoção da CL ao ensino de língua materna, acrescentando, em seus estudos, a promoção do conhecimento metalinguístico.

Para o autor Gursoy (apud JAMES \& GARRET, 1992, p. 1), a CL dentro de uma abordagem multilíngue abre espaço para as línguas minoritárias, permitindo que se veja o multilinguismo e a língua de imigração como uma oportunidade e não como algo que interfira na aprendizagem do aluno. Segundo o autor, contudo, os projetos envolvendo CL não devem ser direcionados apenas para alunos de famílias imigrantes, mas sim para todos os alunos, de modo geral, pois também estes devem ser preparados para uma convivência multicultural e multilíngue. 
Com base nessa reflexão, acreditamos que se deva pensar, também no Brasil, uma didática do multilinguismo que explore a grande variedade linguística existente no país.

\section{A Didática do Multilinguismo}

Entende-se por Didática do Multilinguismo (do alemão "Didaktik der Mehrsprachigkeit", conforme Wiater, 2006; Hufeisen e Neuner, 2003; Pupp Spinassé, 2014) uma abordagem de ensino em que se trabalhe, com o aprendiz, mais de uma língua, simultaneamente, levando-se em conta os diferentes sistemas com os quais o aluno possa estar (ou possa vir a estar) em contato. Por meio dessa abordagem multilíngue (CANDELIER et al., 2004), busca-se fornecer um suporte para a formação de uma competência plurilíngue e pluricultural ao aprendiz, na qual ele possa contar com a aptidão que tem de uma determinada língua para estabelecer aptidões em outras línguas. O resultado não é uma justaposição artificial de habilidades, mas sim um sistema de habilidades integradas dentro do mesmo conjunto de competências (CANDELIER et al., 2004, p. 17). Em outras palavras, em uma abordagem multilíngue, o aprendiz é estimulado a utilizar e a transferir os conhecimentos linguísticos que tem em uma determinada língua para a aprendizagem de outra. Essa abordagem temse mostrado efetiva, tanto em países onde existe mais de uma língua oficial, quanto em regiões onde, ao lado da língua majoritária, é falada também uma língua minoritária.

Segundo Skutnabb-Kangas (1988), programas de ensino que incluíram a língua materna minoritária do aluno bilíngue no ensino de línguas alcançaram sucesso em diferentes níveis: além de promoverem o bilinguismo e o desenvolvimento de uma sociedade igualitária e integrada, esses programas permitem que o aluno aprenda a usar a linguagem como um instrumento efetivo para pensar e solucionar problemas em uma língua e a transferir essa capacidade para outras línguas.

Em nossas pesquisas empíricas, realizadas em escolas inseridas em contextos multilíngues de contato $\mathrm{Pt}-\mathrm{Hr}$, sempre procuramos incluir a língua minoritária local, o Hunsrückisch, como estratégia pedagógica para o ensino de alemão como língua adicional (LA). O objetivo é observar como o pré-conhecimento de estruturas do alemão trazidos pelo 
Hunsrückisch contribui para o aprendizado do alemão-padrão. Atividades de sensibilização linguística e contextualização histórica da língua minoritária, bem como trabalhos de reflexão morfofonêmica servem para demonstrar que: 1) os alunos falantes de línguas minoritárias carecem de estímulos que os façam sentir-se valorizados pelo seu capital linguístico; 2) é possível incluir a língua minoritária como um meio (como "língua-ponte" - cf. PUPPSPINASSÉ 2016) para a aprendizagem de uma nova língua, principalmente tratando-se de uma língua próxima3; 3) tal inclusão mostra-se produtiva e eficaz para o aprendizado do alemão-padrão (PUPP SPINASSÉ et al., 2009).

Além de desenvolver aptidões para ouvir, analisar e aprender línguas, a abordagem multilíngue denominada “Despertar para línguas"(CANDELIER et al., 2004) também tem como objetivo promover o desenvolvimento de percepções favoráveis e de atitudes em relação não apenas às línguas e sua diversidade, mas também àqueles que falam a língua e suas culturas. Naturalmente isso se aplica ainda mais para as línguas e culturas de crianças cuja origem linguística e cultural é diferente da majoritária, possibilitando que sejam reconhecidas pela escola. Em suma, acredita-se que uma abordagem voltada à pluralidade linguística desenvolva no aprendiz o interesse e a curiosidade para com as línguas e as culturas, a confiança nas suas próprias capacidades, a competência de observação/análise de qualquer língua e a capacidade de se sensibilizar e compreender as línguas na complexidade das relações que estabelecem com variações de ordem cultural (CANDELIER et al., 2004).

Para implementar uma Didática do Multilinguismo, a partir de um modelo de CL, podemos nos inspirar no exemplo bem-sucedido de Hélot (2006), que durante três anos desenvolveu um trabalho com as culturas e línguas presentes em uma escola do sul da Alsácia, na comunidade de

${ }^{3} \mathrm{O}$ Hunsrückisch é uma língua próxima do alemão-padrão, devido à semelhança e ao parentesco. O Hunsrückisch compartilha muitos traços em seu corpus com a língua alemã e mantém regularidades nas diferenças (cf. STEFFEN, 2008).
Didenheim. O projeto, que contava com a participação dos pais e professores e abrangia tanto os alunos monolíngues quanto os bilíngues, se desenvolveu com o objetivo de dar legitimidade e igualdade de tratamento para todas as línguas e culturas presentes na escola. $\mathrm{O}$ trabalho consistia em oportunizar aos aprendizes um encontro com diferentes sistemas linguísticos, além de desenvolver a curiosidade para as línguas de diferentes 
partes do mundo, sensibilizando-os para o fato de que uma língua não é inferior ou superior à outra.

Outra forma simples de incluir as línguas minoritárias em atividades pedagógicas de CL seria, com apoio da filologia, através de comparações, buscar elementos que pudessem facilitar a compreensão de como determinadas formas se modificam ao longo do tempo. Por exemplo, em Hunsrückisch, para a palavra "avião", fala-se Luftschiff, que, traduzindo, seria algo como "navio do ar" ("aeronave"); já na língua padrão falase Flugzeug, cuja tradução literal seria "objeto que voa". Ou seja, mostrar para o aluno como a ideia de um e outro vocábulo é semelhante faz com que ele compreenda a legitimidade do uso de "Luftschiff" em Hunsrückisch, por exemplo. Levando questões como esta para a sala de aula, os alunos teriam a oportunidade de compreender a pluralidade das línguas, bem como de ser capazes de prever outras variações e padrões linguísticos.

Essas iniciativas, para promover uma prática de CL no ensino de LA em contextos de uso do Hunsrückisch, são uma forma de reconhecimento e de garantia dos direitos linguísticos da língua minoritária.

\section{O Contexto}

Na região sul do Brasil, a língua alemã, ao lado do inglês, é uma das línguas estrangeiras com mais procura no mercado, não somente porque a Alemanha é uma grande potência mundial e possui forte vínculo comercial com o Brasil, mas também pela forte identificação cultural e linguística. Apesar desses fatores, contudo, o ensino do alemão-padrão costuma ser homogêneo em todas as regiões e, geralmente, não são levadas em conta as especificidades do contexto cultural e linguístico do aprendiz (PUPP SPINASSÉ, 2005).

Gass e Selinker (2008, p. 280) apontam o contexto como fator importante, pois a língua deve ser vista dentro de um contexto social, e não isoladamente, como se fosse um fenômeno individual. Isso nos faz atentar para a importância de considerar o contexto e o pré-conhecimento linguístico (provenientes da L1) do aluno ao aprender uma língua estrangeira, principalmente em se tratando de línguas próximas. Segundo Ammon (1978), porém, a escola costuma 
${ }^{4}$ Disponível em <http:// jaling.ecml.at/default. html> - Último acesso em 04 de janeiro de 2017. ${ }^{5}$ Disponível em <http:// www.ua.pt/cidtff/lale/ Default.aspx> - Ultimo acesso em 04 de janeiro de 2017. negar a realidade sociolinguística dos aprendizes, o que acarreta, muitas vezes, conflitos de identidade.

Em contextos como o de contato $\mathrm{Pt}-\mathrm{Hr}$, a escola pode desempenhar papel fundamental nas atitudes linguísticas. Se a noção de erro, por exemplo, estiver deturpada e o professor não souber quando, e principalmente, como intervir no "erro" do aluno (as interferências do Hunsrückisch, por exemplo), além de poder desestimulá-lo no aprendizado, pode também interferir em sua autoafirmação identitária. Por isso, buscamos, em nossas pesquisas, testar a validade de atividades voltadas ao desenvolvimento da CL e da Didática do Multilinguismo, de modo que a língua minoritária possa encontrar espaço na sala de aula para mostrar seu valor.

Baseamos as atividades realizadas em sala de aula em projetos já existentes, como o projeto Ja-Ling4 (do latim Janua Linguarum, que significa A porta das linguas), que surgiu em 2000, coordenado por M. Candelier, com o objetivo de fazer com que o aluno desenvolva uma atitude positiva em relação à diversidade linguística e desenvolva habilidades metalinguísticas que possam ser usadas para aprender outras línguas; e o projeto LALE (Laboratório Aberto para a Aprendizagem de Línguas Estrangeiras) ${ }^{5}$, o qual, considerando a existência de um lapso entre universidade-pesquisa-escola-professor-aluno, foi criado em 1999 na Universidade de Aveiro, Portugal, com o objetivo de desenvolver, testar e avaliar estratégias e materiais de ensinoaprendizagem de línguas, trabalhando em torno de conceitos como a competência plurilíngue.

Nossa pesquisa empírica foi realizada em turmas de duas diferentes escolas de dois municípios diferentes (Nova Petrópolis e Morro Reuter). Trabalhamos com alunos do segundo segmento do Ensino Fundamental, abordando tanto alunos monolíngues quanto multilíngues, que têm aulas de alemão-padrão na escola.

A metodologia utilizada na pesquisa foi de natureza aplicada e a análise teve tanto uma abordagem quantitativa quanto - em maior escala - uma abordagem qualitativa (KÄFER, 2013).

A pesquisa teve três procedimentos metodológicos distintos - observação em sala de aula, aulas-teste e aplicação de questionário. As observações em sala de aula, realizadas como trabalho de campo, envolveram anotações de campo 
durante as observações, a redação das notas de campo, a coleta de materiais diversos (como, por exemplo, cópias utilizadas para o desenvolvimento de tarefas) obtidos no cenário da pesquisa e a realização de entrevistas informais. Neste artigo, trataremos apenas da aplicação das atividades nas aulaspiloto, já que uma análise das observações e do questionário demandaria uma maior discussão.

\section{A pesquisa-ação}

A proposta das aulas ministradas foi testar as atividades que apresentaremos a seguir, avaliando, através dos questionários e, principalmente, das observações registradas em diário de campo, a efetividade das mesmas. Relataremos aqui os pontos mais importantes observados durante as atividades.

\subsection{Atividade 1: "O aluno e suas origens"}

A primeira atividade, intitulada "O aluno e suas origens Cada um tem a sua história", tinha como objetivo desenvolver a sensibilização e o respeito do aluno para com a história e a cultura do colega, a partir dos nomes de família existentes na turma. O participante era convidado a apresentar para a turma a origem e o significado de seu sobrenome, a partir de pesquisa realizada com a família, previamente solicitada por nós. A atividade também pretendia desenvolver a competência metalinguística do aluno, para que ele tomasse ciência de que, recorrendo ao seu pré-conhecimento linguístico, ele poderia encontrar pistas para a aprendizagem do alemão-padrão.

Para esse segundo objetivo, a ideia era aproveitar os sobrenomes de origem alemã, que, como os outros, eram escritos no quadro, para conduzir com os aprendizes uma reflexão morfofonêmica, comparando os sobrenomes com outras palavras que eles têm em alemão. Por exemplo, o sobrenome "Schneider" contém o encontro vocálico -ei, que é pronunciado como <ai> (['Jnajde]), e o sobrenome "Neumann" contém o encontro vocálico -eu, que tem som de <ói> (['nojman]) - regras praticamente invariáveis no alemão standard. Assim, fazíamos paralelos entre o que eles já sabiam de alemão-padrão, mas que nem haviam se dado conta de que sabiam. 
${ }^{6}$ Utilizamos algumas vezes aqui o termo "dialeto" para nos referirmos ao Hunsrückisch, por ser a forma mais utilizada pelos participantes da pesquisa para se referirem à língua minoritária, mas sem dar ao termo a conotação negativa que ele muitas vezes possui concebendo-o como sinônimo de "língua" ou "variedade".

7 Tanto nome quanto s o brenome s ão pseudônimos.
À medida que as crianças se apresentavam, era interessante perceber a surpresa dos colegas de classe ao verem surgindo no quadro sobrenomes de origem árabe, espanhola, polonesa, "brasileira", italiana, etc. Um participante, inclusive, comentou: "Olha, e todo mundo pensa que só tem alemão em Nova Petrópolis". Ficou claro, pelas reações dos aprendizes, que o trabalho com a pesquisa da origem e do significado dos sobrenomes propiciou uma espécie de autodescobrimento da turma.

A participação foi ainda mais efetiva e demonstrou ser também muito motivadora na realização do trabalho morfofonêmico, a partir dos sobrenomes de origem alemã - e a colaboração foi mais efetiva por parte dos alunos falantes de Hunsrückisch, já que os não falantes do "dialeto ${ }^{6 "}$, afirmando não saber "alemão", mostravam-se resistentes.

Para fins de testagem, em uma das turmas questionamos a uma aluna monolíngue em português qual era o sobrenome do colega Lucas ${ }^{7}$, que era de origem alemã. Prontamente ela respondeu "Eich", pronunciando o encontro vocálico /ei/ com som de /ai/, como no alemão-padrão. Sublinhamos no quadro o encontro vocálico desse sobrenome. Logo após, escrevemos no quadro a palavra "Wein" e, alertando a turma de que somente a colega deveria responder, solicitamos que ela pronunciasse o que acabáramos de escrever. Como já esperado, ela pronunciou [vajn]. Em tom amistoso, então, foi dito a ela que aproveitasse a "cola" que estava no quadro (apontando para a palavra "Eich"), e a participante rapidamente se corrigiu e falou [vajn].

Com tal atividade, procurava-se demonstrar para os participantes, também para os que não falam a língua minoritária, que, usando o conhecimento linguístico adquirido na comunidade, é possível obter pistas para o aprendizado do alemão-padrão na escola; características linguísticas presentes na região não devem representar um obstáculo, mas sim um apoio para aquisição de uma nova língua.

A tarefa mostrou-se bem-sucedida, uma vez que não só despertou essa consciência linguística nos alunos, mas também deu a eles a noção de que o Hunsrückisch pode ser um benefício para o aprendizado do alemão standard, contribuindo para uma atitude linguística mais positiva em relação à língua. 


\subsection{Atividade 2: "As línguas no mundo"}

A segunda atividade, sob o título "As línguas no mundo: Despertando a sensibilização para a diversidade linguística", tinha como objetivo despertar a curiosidade do aluno para a diversidade linguística, motivando-o a estar aberto a novas línguas, bem como a demonstrar a relação geográfica das línguas, debatendo sobre as diferentes origens e famílias linguísticas. Ainda no campo da metalinguagem, era nosso intuito também promover a intercompreensão, para que o aluno visse como se tornar apto a compreender outras línguas.

$O$ roteiro de tal atividade consistiu em afixar no quadro um mapa-múndi e espalhar sobre a mesa do professor imagens referentes a cada país, cuja língua os alunos ouviriam a seguir. Utilizamos, para tal, diversas gravações da música "Ai se eu te pego", do cantor Michel Teló, em diferentes línguas. Explicamos aos participantes que cada língua só apareceria uma vez, então eles deveriam prestar atenção, a fim de identificar a língua que estavam ouvindo. Como eram várias versões (nesta ordem, japonês, árabe, Hunsrückisch, inglês, espanhol, alemão, hebraico e mandarim, todas acessíveis pelo youtube), a canção não era tocada inteira, apenas até acabar o primeiro refrão.

Após ouvir cada uma das versões, era solicitado aos aprendizes, divididos em grupos, que identificassem a língua que ouviram e escolhessem, dentre as imagens dispostas sobre a mesa, aquela que julgavam corresponder a um país de fala de tal língua, fixando-a no quadro (seguindo a disposição dos países conforme o mapa-múndi, como havíamos acordado) e escrevendo o nome da língua.

A versão em Hunsrückisch, gravada pelo grupo "Só alegria", do interior do Rio Grande do Sul, quase que por unanimidade nas turmas, rapidamente foi identificada como sendo "alemão". Foi interessante observar que, no momento em que a música começou a tocar, houve um entusiasmo geral, talvez por esta versão já ser bastante conhecida na região e pela identificação com o estilo "bandinha", dança típica das festas nas comunidades de imigração alemã. Já na versão alemã da música, os grupos tiveram mais dificuldades em identificar a língua e acabaram dando as mais variadas sugestões. Isso provavelmente se deve ao fato de que os 
alunos, os quais anteriormente identificaram a música cantada em Hunsrückisch como sendo língua alemã, descartaram a possibilidade de se estar repetindo uma língua, conforme havia sido explicitado no início da atividade.

É importante ressaltar que essa atividade motivou todas as turmas. Os alunos ficaram debatendo entre si as suas opiniões a respeito das línguas que ouviram. Em alguns casos, solicitaram ouvir algumas das músicas novamente, para poder distinguir melhor entre determinadas línguas. Em uma turma de Nova Petrópolis, um aluno bilíngue $\mathrm{Pt}-\mathrm{Hr}$, ao ouvir pela segunda vez a versão em Hunsrückisch, acabou por identificála como "o nosso dialeto", por reconhecer algumas palavras da língua. Em Morro Reuter, também um aluno bilíngue identificou a letra como sendo "o alemão que a gente fala aqui". O intuito, com as duas versões distintas, era realmente leválos a enxergar as duas línguas como coisas distintas, o que foi sendo paulatinamente alcançado com as reflexões.

Quanto às outras versões da música, em alguns grupos houve também grande discussão, mas em algumas turmas houve menos reflexão, e os grupos apenas "chutavam" as línguas, sem parar para prestar atenção ou refletir sobre o que estavam ouvindo. Os alunos de todas as turmas apresentaram dificuldade para distinguir as versões chinesa e japonesa - o que já era esperado. Todos chegaram à conclusão de que são duas línguas totalmente diferentes das outras que ouviram, mas muito parecidas entre si.

Aproveitamos o ensejo, então, para promover com os alunos uma reflexão acerca das famílias linguísticas e da variação da língua no tempo e no espaço, falando de suas causas e efeitos, fazendo as seguintes perguntas: "O alemão da Alemanha e o dialeto falado aqui na região são a mesma língua ou são línguas diferentes?"; "São da mesma família?"; "Como explicar que duas línguas tão distantes geograficamente sejam tão semelhantes?". Houve casos em que os aprendizes, de pronto, respondiam a essa última pergunta, dizendo que uma das causas seria a imigração.

Quando questionados se o Hunsrückisch poderia ser considerado alemão, na maioria das turmas os alunos defenderam que alemão standard e Hunsrückisch são duas línguas diferentes, que a primeira era mais usada para a 
escrita e a segunda, mais para a oralidade. Alguns alunos complementavam com comparações, dizendo que era como no português: "A gente fala de um jeito e escreve de outro". Também apareceram manifestações como: "A língua que a gente fala aqui é mais simples, esse alemão que a gente aprende na escola é mais chique". Nesse momento, questionamos sobre o que a turma achava, e outro aprendiz já rebateu, dizendo: “Claro que é a mesma língua, só que a gente pronuncia diferente as palavras".

Em ambas as escolas, explicamos que o alemão-padrão e o Hunsrückisch são duas línguas distintas, mas com características em comum, pois são originárias da mesma família (esta se originou daquela). Indagamos, então, se uma dessas línguas era a mais correta e, na escola de Nova Petrópolis, os alunos logo fizeram questão de ressaltar que não existe uma língua mais certa que a outra e que, portanto, falar o dialeto não significa falar errado. Tal postura pareceu ser algo já internalizado por eles a partir do discurso da professora, que, tanto nas nossas conversas informais quanto no preenchimento do questionário, demonstrou ter uma grande consciência linguística e interesse em desenvolvê-la com os alunos.

Com todas as turmas, questionamos de onde havia surgido o Hunsrückisch falado na região e a resposta geral foi: "daqui". Desse modo, fizemos uma breve contextualização, de forma resumida, sobre a história da imigração alemã para o sul do Brasil, salientando a origem geográfica e histórica do Hunsrückisch, nome esse que, aparentemente, desconheciam até então, explicando que se trata de uma língua brasileira de origem alemã (PUPP SPINASSÉ, 2016, p. 108).

O passo seguinte da atividade consistiu em os alunos completarem dois quadros, que os participantes receberam impressos, cada um com uma frase escrita em diferentes línguas (Frase 1: "Meu nome é Maria"; Frase 2: "Eu gosto de maçã"). Eles, então, em duplas, foram orientados a identificar as línguas, completando as lacunas. Então, foi solicitado que observassem as frases e lacunas que haviam completado, atentando para as semelhanças e diferenças entre as línguas (quadro 1). 
Quadro 1. Quadro de idiomas da Frase 1

\begin{tabular}{|c|c|}
\hline FRASE 1 & IDIOMA \\
\hline MEU NOME É MARIA & PORTUGUÊS \\
\hline \multicolumn{2}{|l|}{ MY NAME IST MARIA } \\
\hline & ALEMÃO \\
\hline & HUNSRÜCKISCH \\
\hline \multicolumn{2}{|l|}{ MI NOMBRE ES MARIA } \\
\hline \multicolumn{2}{|l|}{ 私の名前はメアリーです } \\
\hline 我的名字是Mary & MANDARIM \\
\hline ايرام يمسا & $A ́ R A B E$ \\
\hline הירמ אוה ילש םשה & \\
\hline
\end{tabular}

Fonte: elaboração própria.

Ao concluírem a tarefa, continuando a reflexão linguística, indagamos: "Quais línguas são totalmente diferentes?"; “O que faz uma língua ser diferente da outra?"; "Quais línguas vocês notaram que são mais parecidas?"; "Existem palavras que são iguais ou parecidas em algumas línguas? Quais? Por quê?". Também aqui pudemos tecer uma reflexão acerca das famílias linguísticas, de modo a reforçar o que já havia sido comentado com eles na etapa anterior.

Pudemos observar o notório desenvolvimento de uma consciência linguística por parte dos alunos, principalmente dos bilíngues $\mathrm{Pt}-\mathrm{Hr}$, que em todas as atividades procuravam se manifestar e dar a sua opinião.

\subsection{Atividade 3: "Sacola-surpresa"}

Na terceira atividade, para a qual demos o nome de "Sacola-surpresa", foram selecionados alguns objetos que levamos para a sala de aula. Esses objetos foram colocados dentro de um saco não transparente e foi solicitado que um aluno por vez fosse até a sacola e, de olhos fechados, colocasse a mão dentro dela, escolhesse um objeto e, pelo toque, tentasse adivinhar o que era. Ao descobrir, o aluno deveria falar o nome do objeto em Hunsrückisch e/ou em alemão-padrão, e nós listávamos as palavras no quadro em ambas as línguas e também em português. 
Se alguém não soubesse responder, podia pedir ajuda aos colegas. Os alunos bilíngues, sem exceção, souberam nomear os objetos em Hunsrückisch, porém, em algumas turmas, havia o desconhecimento dos termos em alemão standard, de modo que acabávamos fornecendo as respostas. Em todas as turmas, os alunos monolíngues não souberam nomear os objetos na variedade local, solicitando a ajuda dos colegas bilíngues Pt-Hr.

Como já era esperado, quando um aluno retirou da sacola um vestido, sendo falante bilíngue $\mathrm{Pt}-\mathrm{Hr}$ ativo, logo falou "Oh, das is en Rock" ("Ah, é um Rock"). Confirmamos, dizendo que no dialeto falamos "Rock", e perguntamos como seria a denominação em alemão-padrão. Não obtendo a resposta, nós a fornecemos para a turma. Propositalmente, havia na sacolasurpresa também uma saia, a qual, em Hunsrückisch, também é denominada Rock. Assim, ao definir o objeto em mãos no Hunsrückisch, o aluno disse "Um Rock, também", ninguém sabendo nomear o objeto na língua alemã.

Desse modo, as palavras foram sendo listadas no quadro, conforme o quadro 2:

Quadro 2. Objetos da Sacola-surpresa

\begin{tabular}{|c|c|c|}
\hline Objeto (em português) & $\begin{array}{c}\text { Denominação em } \\
\text { Hunsrückisch }\end{array}$ & $\begin{array}{c}\text { Denominação em alemão- } \\
\text { padrão }\end{array}$ \\
\hline prato & teller & teller \\
\hline boneca & popp & puppe \\
\hline óculos & brill & brille \\
\hline carro & karre/audo & auto \\
\hline livro & buch & buch \\
\hline colher & leffel & löffel \\
\hline celular & celular/telefon & handy \\
\hline vestido & rock & kleid \\
\hline saia & rock & rock \\
\hline avião & luftschiff & flugzeug \\
\hline bola & kuchel/bola & ball \\
\hline guarda-chuva & scherm & regenschirm \\
\hline ovelha & schoof & schaf \\
\hline
\end{tabular}

Fonte: elaboração própria. 
A partir dessa tabela resultante dos dados, refletimos com os alunos sobre as semelhanças do Hunsrückisch com a língua alemã standard, bem como sobre os possíveis motivos das diferenças, identificando regularidades na língua minoritária.

Além dessa reflexão, objetivou-se com essa tarefa também desenvolver no aluno bilíngue Pt-Hr a autoestima, ao verem que sua língua materna pode lhes fornecer algumas pistas na aprendizagem do alemão standard e que seu vocabulário pode contribuir para a aquisição do vocabulário na LA. Também queríamos, com a atividade, desenvolver nos aprendizes monolíngues a sensibilização para com a variedade linguística falada na comunidade, promovendo uma discussão acerca das línguas e variedades.

Essa atividade foi muito bem recebida pelos participantes, pois a sacola, que chamava a atenção pelo tamanho, despertava a curiosidade. Os aprendizes apresentaram comportamento bastante agitado, fazendo suposições. Porém, quando pedimos a palavra, todos silenciaram para ouvir qual seria o trabalho a seguir.

Em turmas maiores, quando havia mais participantes do que objetos na sacola, recolocamos os objetos todos novamente na sacola, para que o restante da turma também participasse da tarefa. Apesar de repetir os objetos já denominados pelos colegas, o restante da turma manteve-se motivada com a atividade, o que acabou servindo como um reforço do que fora visto inicialmente.

\subsection{Atividade 4: "A Morada das línguas"}

Certamente existem línguas com as quais temos mais contato, outras menos. Algumas das quais gostamos mais, outras menos. Algumas, também, achamos mais difíceis, outras, mais fáceis. Partindo desse pressuposto, a quarta e última atividade, sob o título "A Morada das línguas", foi promovida a fim de verificar a relação dos alunos com a sua língua e com as línguas da comunidade.

Tal atividade desenvolveu-se da seguinte forma: foi distribuída uma folha de ofício em branco para os alunos. Nela, eles deveriam desenhar a si mesmos e, para as partes do seu corpo, citar uma língua, justificando, por escrito, o 
motivo pelo qual escolheram atribuir para aquela parte do corpo determinada língua. A fim de exemplificar, uma das pesquisadoras explicou que, em seu coração, ela colocaria o Hunsrückisch, pois era a língua dos seus avós, a quem ela amava muito. E assim a atividade se seguiu, com as crianças elegendo partes do corpo para as línguas que as rodeiam e refletindo sobre a questão afetiva em relação às línguas.

Em todas as turmas, a grande maioria dos alunos realizou com motivação a tarefa, sendo que alguns a concluíram muito rápido. Para esses casos, foi importante ter uma atividade extra prevista.

Ao analisar os desenhos, é relevante destacar a quantidade de vezes que os alunos (principalmente das localidades mais rurais) fizeram menção à palavra "Hunsrückisch", visto que os grupos, em sua totalidade, pelo que pudemos constatar, vieram a conhecer tal denominação somente durante as atividades das aulas-piloto.

\section{As atitudes linguísticas}

Quanto à atitude dos professores diante da presença da língua minoritária local na escola, podemos afirmar que, nas escolas pesquisadas, há uma postura implícita de aceitação da língua minoritária na sala de aula. Não foram percebidas, durantes as observações, atitudes negativas, tampouco atitudes que estimulassem o uso do dialeto na sala de aula. No entanto, no discurso das professoras entrevistadas, os alunos falantes de Hunsrückisch, segundo elas, apresentam maior facilidade no aprendizado do alemão-padrão.

Durante as aulas observadas, tanto em Nova Petrópolis quanto em Morro Reuter, sempre que algum aluno apresentava alguma dificuldade, as professoras o orientavam a pedir ajuda para algum determinado colega, que em $100 \%$ dos casos era um indivíduo bilíngue. Sob esse aspecto, estudos como o de Pupp Spinassé (2005), Steffen (2008) e Messa (2008) corroboram a atitude das professoras, pois uma variedade pode contribuir para a aprendizagem de uma outra tipologicamente próxima a ela.

Em Nova Petrópolis, a professora, a fim de demonstrar o que estava dizendo sobre a maior facilidade dos alunos bilíngues, 
em certo momento de leitura, solicitou, primeiramente, que dois alunos não falantes de Hunsrückisch lessem um diálogo para o restante da turma. Em seguida, solicitou o mesmo também a uma dupla de alunos bilíngues. Estes últimos, com algumas interferências do dialeto, leram com maior fluidez, maior entendimento e menos dificuldade o texto em relação aos alunos monolíngues. Em Morro Reuter, por sua vez, a professora destacou que é possível ministrar as aulas de alemão como LA utilizando, na grande parte do tempo, a própria língua-alvo, devido ao grande grau de compreensão proveniente do Hunsrückisch - algo que, segundo ela, não seria possível em um contexto de alunos monolíngues.

Já para os participantes monolíngues, como pudemos observar, o fato de os colegas falarem, ao lado do português, o Hunsrückisch, parece ser um fator positivo, pois julgam que a aprendizagem do alemão-padrão se torna mais fácil com o conhecimento do dialeto, sendo ele, portanto, visto como uma vantagem. No entanto, esses participantes sentem que os colegas bilíngues utilizam o Hunsrückisch para excluí-los em determinados momentos, deixando-os, assim, com um sentimento de insegurança, como observamos na relutância em participar de certas atividades orais, com medo de se tornarem alvos de deboche dos demais colegas. Cremos que as atividades desenvolvidas colaborem para quebrar essas atitudes, por meio da sensibilização que propõem.

A ideia de que a aula de alemão-padrão serve para aprender o alemão "correto" também estava presente nos grupos observados, mesmo não sendo a ideia sustentada pelas professoras das turmas. Contudo, apesar das várias oportunidades possíveis, não pudemos ver, durante as observações, nenhuma atividade voltada à conscientização linguística sendo desenvolvida com os alunos. Também os materiais didáticos adotados não contemplam as especificidades locais e em nada privilegiam a pluralidade linguística e cultural do contexto brasileiro.

Assim, acreditamos que as atividades que desenvolvemos nas escolas possam ser um bom estímulo de reflexão didática para os professores, para que estes adotem em sua prática pedagógica atividades que contemplem a CL e visem a uma didática do multilinguismo. 


\section{Conclusão}

As atividades desenvolvidas e aplicadas nas escolas tiveram por objetivo revelar aos alunos a riqueza da diversidade linguística, representada na sala de aula pelos falantes de dialetos, além de mostrar a relação daquela variedade com o alemão-padrão, promovendo uma reflexão metalinguística. Além disso, buscava-se contribuir para o desenvolvimento da sensibilização para com outras línguas e culturas, despertando o interesse deles para a aprendizagem de novas línguas.

Neste artigo, procuramos apresentar algumas estratégias de promoção da conscientização linguística, que visam a garantir uma educação linguística plural. Nossa pesquisa apontou que, ao adotar uma perspectiva de CL em regiões de língua minoritária, é possível promover a diversidade linguística e uma educação plurilíngue e pluricultural, desenvolvendo nos alunos, desde cedo, uma conscientização e uma valorização das variedades linguísticas.

A proposta foi acolhida pelas escolas, com o total engajamento das professoras e interesse dos alunos durante toda a pesquisa. Soubemos, por informantes da comunidade, que o trabalho realizado nas escolas teve repercussão positiva nas famílias das crianças participantes, e tivemos o convite de estendê-lo a outras escolas da região. Esse feedback demonstra que os caminhos para trabalhar com a conscientização linguística e o multilinguismo estão abertos, bastando apenas que se dê o primeiro passo para leva-los às escolas e aplicar na prática o que se tem pesquisado e criado nas universidades. Percebe-se também a importância de envolver a comunidade nessas iniciativas, mesmo que seja indiretamente através da repercussão nas famílias.

Quanto à questão da língua minoritária, percebemos que os aprendizes necessitam apenas de um primeiro estímulo para construir uma atitude positiva em relação à sua língua materna ou às línguas da sua comunidade, bem como para saber utilizar seus conhecimentos linguísticos na aprendizagem de novas variedades. $\mathrm{O}$ interesse que eles demonstraram pelas relações entre as línguas pode representar um argumento a favor de implementar atividades de conscientização linguística nas aulas de línguas nesses contextos ou em contextos semelhantes. 


\section{REFERÊNCIAS}

ALTENHOFEN, C. V. Política linguística, mitos e concepções linguísticas em áreas bilíngues de imigrantes (alemães) no Sul do Brasil. Revista Internacional de Linguística Iberoamericana, v.2, n.1, p.83-93, 2004.

AMMON, U. Schulschwierigkeiten von Dialektsprechern. Basel: Beltz, 1978.

BAGNO, M.; RANGEL, E. O. Tarefas da educação linguística no Brasil. Revista Brasileira de Linguística Aplicada, v.5, n.1, p.6381, 2005.

BASTOS, M.; GONÇALVES, L.; PINHO, A. S.; SIMÕES, A. R. Todas as línguas na aula de línguas: materiais pedagógicos para os $2^{\circ}, 3^{\circ}$ ciclos do ensino básico e ensino secundário. In: CARDODO et al. (org.). Actas do Colóquio "Da Investigação à Prática: interacções e debates". Aveiro: Universidade de Aveiro, DDTE/CIDTFF, 2008. p. 69-91.

BOURDIEU, P.A economia das trocas linguísticas: o que falar quer dizer. São Paulo: Editora da Universidade de São Paulo, 1998.

CANDELIER, M.; OOMEN-WELKE, I.; PERREGAUX, C. Janua Linguarum - A phase in the development of the awakening to languages. In: CANDELIER, M. et al. (Ed.) Janua Linguarum The gateway to languages. The introduction of language awareness into the curriculum: Awakening to languages. Strasbourg: Council of Europe Publishing, 2004. p. 15-38.

DONMALL, G. Language Awareness. Londres: CILT, 1985.

GASS, S. M.; SELINKER, L. Second Language Acquisition: An introductory course. New York: Routledge, 2008.

HAWKINS, E. Foreign language study and language awareness. Language Awareness, v.8, n.3-4, p.124-142, 1999.

HÉLOT, C. Bridging the gap between prestigious bilingualism and the bilingualism of minorities: Towards an integrated perspective of multilingualism in the French education context. In: LAOIRE, M. O. (Org.). Multilingualism in educational settings. Baltmannsweiler: Schneider Verlag Hohengehren, 2006. p. 49-72.

HUFEISEN, B.; NEUNER, G.Mehrsprachigkeitskonzept Tertiörsprachen - Deutsch nach Englisch.Strasbourg: Council of Europe Publishing, 2003. 
JAMES, C. A cross-linguistic approach to language awareness. Language Awareness, v.5, p.138-148, 1996.

JAMES, C.; GARRETT, P. Language Awareness in the Classroom. London/New York: Longman, 1992.

JESSNER, U. Teaching third languages: Findings, trends and challenges. 2008. Disponível em: < http://www.unil. ch/webdav/site/magicc/shared/Ressources/Jessner_2008_ Teaching_third_languages.pdf > - Acesso em: 28 dez. 2016.

KÄFER, M. L. A Conscientização linguística como fundamento para uma abordagem plural no ensino de alemão-padrão como lingua adicional em contextos bilingues português-Hunsrückisch. Dissertação de Mestrado. Porto Alegre: UFRGS, 2013.

MESSA, R. M. O papel do dialeto no desempenho de alunos na prova de proficiência Deutsches Sprachdiplom I. Revista Contingentia, v.3, n.1, p.51-68, 2008.

PUPP SPINASSÉ, K. Deutsch als Fremdsprache in Brasilien. Eine Studie uber kontextabhängige unterschiedliche Lernersprachen und muttersprachliche interferenzen. Frankfurt a.M.: Peter Lang, 2005. PUPP SPINASSÉ, K. Dialekt im Deutschunterricht? Fur eine Didaktik der Mehrsprachigkeit in Brasilien. Fremdsprache Deutsch, n.50, p.25-29, 2014.

PUPP SPINASSÉ, K. Fazendo política linguística em sala de aula: ações didático-pedagógicas pela manutenção da língua minoritária hunsrückisch. Revista Virtual de Estudos da Linguagem - ReVEL, v.14, n.26, p.103-119, março 2016.

PUPP SPINASSÉ, K.; KÄFER, M. L.; MORAES, R. G. A didatização de regras ortográficas do Hunsrückisch como fator de facilitação para o aprendizado do Alemão-Padrão como língua estrangeira. In: Anais do X Seminário Nacional de Pesquisadores da História das Comunidades Teuto-brasileiras. Porto Alegre: Corag, 2009. p. 300-307.

RIBEIRO, C. Metacognição: Um Apoio ao Processo de Aprendizagem. In: Psicologia: Reflexão e Crítica, v.16, n.1, p.109116, 2003.

SCHNEIDER, M. N. Atitudes e concepções linguísticas e sua relação com as práticas sociais de professores em comunidades bilingues alemão-português do Rio Grande do Sul. Tese de Doutorado. Porto Alegre: UFRGS, 2007. 
SKUTNABB-KANGAS, T. Multilingualism and the education of minority children. In:SKUTNABB-KANGAS, T;;CUMMINS, J. (Ed.) Minority education: from shame to struggle. Clevedon, Avon: Multilingual Matters, 1988. p. 9-44.

STEFFEN, Joachim. A Vantagem de falar dialeto: aproveitar as variedades não-padrão para a construção de comunidades multilíngues. Revista Contingentia, v.3, n.2, p.67-76, 2008.

WIATER, W. (Org.) Didaktikder Mehrsprachigkeit. Theoriegrundlagen und Praxismodelle. Munchen: Vögel, 2006. 


\section{Abstract \\ Language awareness and didactics of multilingualism in Portuguese-Hunsrückisch contact contexts}

Hunsrückisch is one of the most widely spoken immigration languages in Brazil, having already become official in two Brazilian cities (Antônio Carlos, in Santa Catarina, and Santa Maria do Herval, in Rio Grande do Sul). In general, therefore, some actions in the field of linguistic policies and linguistic rights have been taken, in order to promote the respect towards the linguistic and cultural diversity of the contact regions Hunsrückisch-Portuguese. Among these actions are some research projects that investigate both the language practices and the attitudes present in these regions, seeking to collaborate in maintaining the language and the identity that were inherited from the immigrants. Thus, the present article brings some results of a research carried out in two schools of different Hunsrückisch speaking communities, whose purpose was to use linguistic awareness to arouse sensibility and respect to different varieties. The aim of this work was to identify ways that contribute to the development of positive attitudes towards the linguistic diversity (including, in this case, minority languages), thinking the foundations for a didactics of multilingualism, that use local languages and culture in order to rich other languages of interest.

Keywords: Language Awareness. Hunsrückisch. Language Policy. Didactics of Multilingualism. Language Attitudes. 